\title{
INVESTIGATING BARGAINING POWER OF FARMERS AND PROCESSORS IN IRAN'S DAIRY MARKET
}

\author{
ZEINAB SHOKOOHI* \\ Department of Agricultural Economics, College of Agriculture, Shiraz University, Shiraz, Iran \\ AMIR HOSSEIN CHIZARI \\ Department of Agricultural Economics, College of Agriculture and Natural Resource, University of Tehran, Tehran, Iran \\ MAHDI ASGARI \\ Department of Agricultural Economics, University of Kentucky, Lexington, Kentucky
}

\begin{abstract}
The farm-gate price of raw milk in Iran is determined annually in negotiations among representatives of dairy processors, milk producers, and government officials. This study estimates the average bargaining power of dairy farmers and processors, through applying the generalized axiomatic Nash approach in a bilateral bargaining model. We employ annual data from 1990 to 2013 to estimate econometric representation of a bilateral bargaining model using a Monte Carlo expectation maximization algorithm. Results imply a higher bargaining power of 0.69 for processors, compared with 0.31 for farmers. This asymmetry of bargaining power causes unequal allocation of gains in the milk market.
\end{abstract}

Key words. Bargaining power, bilateral monopoly, dairy, milk, Iran

JEL Classifications. C78, D43, Q13

\section{Introduction}

The food processing industry has changed dramatically in Iran during past decades. Economies of scale and increased concentration have led to fewer and larger agribusinesses. In this situation, the main concern is that greater bargaining power enables the processors to absorb more of the profit and leave the farmers disadvantaged. Policy makers are concerned about farmers' low income and unfavorable socioeconomic problems, which could be exacerbated by the unbalanced bargaining power in agricultural markets. The dairy industry in Iran is a good example of a concentrated industry with possible asymmetric bargaining power for farmers and processors.

\footnotetext{
*Corresponding author's e-mail: z_shokoohi@shirazu.ac.ir
} 
More than 20,000 dairy farms across the country produced 5.9 million tons of raw milk in 2013 compared with almost 2 million tons in 1990, which is an $8.12 \%$ average annual increase. However, there are only about 600 dairy processors in Iran. ${ }^{1}$ According to Iran's Ministry of Industry, Mine, and Trade (MIMT), approximately $70 \%$ of the raw milk ${ }^{2}$ is bought by less than $9 \%$ of the dairy processing factories (MIMT, 2013). Nearly $85 \%$ of the raw milk is processed into pasteurized milk, yogurt, and cheese. The value added by the dairy industry is estimated at US\$4 million per year, about $20 \%$ of the total contribution by the food industry in Iran. The seven largest companies benefit from $65 \%$ of the market share. For instance, Pegah Company controls $30 \%$ of the market in dairy products by processing 6,000 tons of raw milk per day.

Each year, the raw milk price is decided through negotiations among representatives of dairy farmers and processors, and that price is announced by the government. The main objective of the negotiations is to determine the price at the national level. The negotiation for setting the price normally starts in March and April. ${ }^{3}$ However, each party can call for renegotiations later in the year. When the demand or supply of milk and other dairy products changes considerably, the price of raw milk is revised. Policy makers may encourage or discourage renegotiations depending on the short-term inflation rate and other economic concerns. Dairy farmers pursue the highest attainable price for raw milk in the negotiations. On the other hand, processors bargain for the lowest possible price. In this situation, the bargaining power of each party determines its gain from trade. Clearly, players with greater bargaining power benefit more from the negotiated price.

The role of government is rather complex in the negotiations. The government facilitates the negotiations, hoping to create a fair condition for both sides. It also expects the negotiations to reach a reasonable price for raw milk. The government influences the negotiated price of raw milk directly through the policies set by the Consumers and Producers Protection Organization (CPPO), which is a semigovernmental organization under Iran's MIMT. The main objective of the CPPO (2016) is to "determine, adjust and fix the prices of domestic products and imported goods and services ... and prevent the inappropriate increase in the prices."

Higher prices for raw milk diminish the processors' margin and raise prices of dairy products, generating inflationary impacts. Therefore, the main concern of the officials who facilitate the negotiation is to keep the price of raw milk within

1 There are no clear statistics on the distribution of private, semigovernment, and government-owned enterprises in this industry.

2 We use raw milk to refer to farmers' product and pasteurized milk for the processors' product.

3 Early months of the Persian calendar.

4 Refer to the history of CPPO available at: http://cppo.mimt.gov.ir. 
a reasonable range that would not cause an unexpected increase in the price of dairy products.

Lower prices, on the other hand, reduce the farmers' margin and significantly lower their income. The government has been distributing feed and fodder to dairy farms at considerably subsidized prices to reduce the production cost of raw milk and therefore the price requested by farmers. The distribution of subsidized inputs by the government has indirectly influenced the negotiated price of raw milk. In our model, we use adjusted prices for the concentrated feed to control for government subsidies in this sector.

Farmers have been complaining about the price of raw milk and the level of dried milk importation in the past decade. Despite government officials often representing them in the negotiations, farmers believe that they have lost their bargaining power to processors. Processors, on the other hand, disagree and believe government officials favor farmers. This debate has remained unresolved. It seems that the basic unanswered question is whether dairy farmers have equal bargaining power against processors in Iran's market. The goal of this article is to investigate the bargaining power of dairy farmers and processors in milk price formation in Iran.

Previous studies of Iran's dairy market have focused mostly on the demand for dairy products (Chizari et al., 2015; Pishbahar and Kheiri Netaj-Firozjah, 2015), the horizontal market (Chizari, Shokoohi, and Salami, 2018), and the price transmission between farmers and processors (Ahmadi Shadmehri and Ahmadi, 2010; Moghaddasi and Rahimi, 2013). In the price transmission studies, assumptions on the bargaining power of the agents are used to interpret the empirical results. Although price transmission models explain the transfer of price shocks among various levels of the market, they provide no evidence of the underlying reasons for and the implications of the symmetric/asymmetric price transmissions. Furthermore, these models are limited in explaining price formation under the negotiation conditions. This caveat can be addressed through bargaining models.

There are a considerable number of studies on the application of bargaining theory in the literature. ${ }^{5}$ However, fewer studies (Bonnet and BouamraMechemache, 2015; Folwell, Mittelhammer, and Wang, 1998; Noton and Elberg, 2014; Oczkowski, 1991; Prasertsri and Kilmer, 2008) report application of this theory to the agro-food industry. Bonnet and Bouamra-Mechemache (2015) investigate the distribution of profit between producers and retailers in the supply chain of organic milk. They calculate the retailers' margin based on a fixed retail price and then analyze the bargaining power using detailed cross-section data.

Prasertsri and Kilmer (2008) examine the relative bargaining power of one marketing cooperative and several processors in the U.S. dairy industry using regional data. They use a Nash bargaining model to analyze the negotiated price

5 Refer to Napel (2002) and Suh and Wen (2006) for literature review. 
in the Florida raw milk market. Both Bonnet and Bouamra-Mechemache (2015) and Prasertsri and Kilmer (2008) employ single-equation regression models to relate observed prices to a series of exogenous factors that are thought to influence bargaining power.

Similar to previous studies, we apply the bargaining theory to the food processing industry in general and the dairy market in particular. However, our study is different from the former ones in two main aspects. First, the type of the data in this study differs from Bonnet and Bouamra-Mechemache (2015) and Prasertsri and Kilmer (2008). We use annual longitudinal data at the national level because cross-section data at the retailer level are not available and monthly or quarterly data on milk production are not reported in Iran.

Second, both previous studies use a single-equation model to define the bargaining model. The caveat of this approach is that one cannot observe the factors that affect negotiators' behavior and thus examine the relationship between those factors and the settled price. We, in contrast, define the bargaining model using a system of equations that represent the supply, the demand, and the negotiated price of raw milk.

Finally, many previous studies, including Bonnet and Bouamra-Mechemache (2015), assume the competitive horizontal market for both agents. This assumption may bias the results when studying markets like Iran in which concentration is ever increasing. We relax this assumption and estimate the reservation prices ${ }^{6}$ to examine the vertical market for raw milk.

\section{Theoretical Framework}

According to Muthoo (1999, p. 2), "bargaining is any process through which the players on their own try to reach an agreement." Bargaining can be bilateral or multilateral depending on whether two or more agents are involved in the process. Previous studies investigate either the general economic theory of bargaining or how it is modeled in the context of a specific industry. Furthermore, bargaining problems can be analyzed theoretically using axiomatic or strategic approaches. The axiomatic approach considers a unique solution, referred to as symmetric Nash bargaining, to a set of axiomatic assumptions (Nash, 1950). In other words, when a two-person bargaining problem satisfies the axioms of scale invariance, symmetry, efficiency, and independence of irrelevant alternatives, the Nash bargaining solution is the unique solution.

Roth (1979) extends the axiomatic approach to solve for asymmetric Nash bargaining solutions. However, this approach does not provide the details of the bargaining process such as the bargaining periods and the number of the suggested strategies. Rubinstein (1982) introduces the strategic approach, which addresses more details of the bargaining process, and Roth (1985) adds a risk

6 That is the supply reservation price and demand reservation price. 
component to this approach. Binmore, Rubinstein, and Wolinsky (1986) advance the relationship between axiomatic and strategic approaches. Oczkowski (1991) proposes a method to describe agents' behavior under disequilibrium situations. Although this method is originally applied to disequilibrium in markets with quantity controls, the application can be broadened to nonquota equilibrium markets.

We extend the framework proposed in Oczkowski (1991) to model the bargaining environment and determination of milk prices in Iran. To the best of our knowledge, there is no previous research that has modeled price determination in Iran's agro-food sector in general and the milk market specifically, using a bargaining framework.

In bilateral bargaining, two players (agents) have incentives to increase their joint payoffs while competing for higher gains. In this study, bilateral bargaining refers to the negotiations between (representatives of) the farmers and the processors to determine the national price of raw milk. Because there is no friction in the offer process and the settled price does not depend on the duration of negotiations, the generalized axiomatic Nash approach is used to characterize the bargaining process.

The generalized axiomatic Nash approach is the asymmetric form of a Nash solution. It is proper to use this model when the symmetry assumption does not hold for the game. The following function $N$ represents the generalized Nash bargaining model for price negotiation between two players:

$$
N=\max \left(\pi_{1}-d_{1}\right)^{\tau}\left(\pi_{2}-d_{2}\right)^{1-\tau},
$$

where $\pi_{1}$ and $\pi_{2}$ are the payoffs for the farmers and the processors upon reaching an agreement. In the case where the bargaining process fails, the outcomes for the farmers and the processors would be $d_{1}$ and $d_{2}$, respectively. Similar to Bonnet and Bouamra-Mechemache (2015), the $d_{i}$ 's are the payoffs that could be realized outside the negotiations. In that case, farmers could potentially seek other buyers, and processors could look for other suppliers. However, the negotiations are held at the national level, and this option is unattainable. Therefore, in practice $d_{1}=d_{2}=0$. The relative bargaining power of farmers is denoted by $\tau$ and that of processors by $1-\tau$ in this model. If $\tau=0.5$, both players have equal bargaining power, and the asymmetric Nash bargaining solution is equivalent to the symmetric solution.

The agreement payoff for each party is a function of negotiated price $P$ and the reservation price, which will be defined as

$$
\begin{array}{ll}
\pi_{1}=P-P^{s} & \text { farmers } \\
\pi_{2}=P^{d}-P & \text { processors }
\end{array}
$$

where $P^{s}$ denotes the minimum price at which farmers are willing to sell the raw milk (i.e., supply reservation price). On the other hand, $P^{d}$ is the maximum 
price at which processors would buy the raw milk (i.e., demand reservation price).

Therefore, farmers prefer any negotiated price above $P^{s}\left(P>P^{s}\right)$, and processors prefer any price below $P^{d}\left(P<P^{d}\right)$. If the suggested price in the negotiations stands below $P^{s}$ or exceeds $P^{d}$, the bargaining process fails. Hence, both parties continue to negotiate until they each gain payoffs greater than zero. Because $d_{1}=d_{2}=0$, equation (1) can be written as follows:

$$
N=\max \left(P-P^{s}\right)^{\tau}\left(P^{d}-P\right)^{1-\tau}
$$

To maximize the generalized Nash bargaining model, we differentiate equation (3) with respect to the negotiated price, $P$, and set the first-order condition equal to zero. Therefore,

$$
P=\tau P^{d}+(1-\tau) P^{s},
$$

which implies that the negotiated price is a function of reservation prices and agents' bargaining power. However, we cannot directly estimate this equation.

In order to estimate the generalized Nash bargaining solution to the bargaining model, following Oczkowski (1991), we define the determinants of demand reservation price, $P^{d}$, and supply reservation price, $P^{s}$, and form a system that lays out the bargaining model as follows:

$$
\begin{aligned}
& P_{t}^{s}=f\left(X_{t}^{s}\right)+u_{t}^{s} \\
& P_{t}^{d}=f\left(X_{t}^{d}\right)+u_{t}^{d} \\
& P_{t}=\tau P_{t}^{d}+(1-\tau) P_{t}^{s}+u_{t}^{p},
\end{aligned}
$$

in which $X_{t}^{d}$ and $X_{t}^{s}$ are nonstochastic independent variables, and $u_{t}^{s}, u_{t}^{d}$, and $u_{t}^{p}$ represent error terms with zero mean and constant variance of $\sigma_{s}^{2}, \sigma_{d}^{2}$, and $\sigma_{p}^{2}$, respectively.

The supply reservation price of milk, $P_{t}^{s}$, is the minimum price that is acceptable by farmers and depends on cost factors and the quantity produced. Feed and labor are the major components of the total cost of milk production, about $70 \%$ and $12 \%$, respectively. We specify the supply of raw milk as

$$
P_{t}^{s}=\beta_{0}+\beta_{1} F C_{t}+\beta_{2} L_{t}+\beta_{3} Q_{t}^{p e}+u_{t}^{s},
$$

where $F C_{t}$ and $L_{t}$ denote the adjusted price of concentrated feed ${ }^{7}$ and the wage rate, respectively. When feed and labor prices rise, we expect farmers to demand a higher price for raw milk in the negotiations. So, feed and labor prices have positive impacts on $P_{t}^{s}$. Hence, higher production cost results in upward pressure on the supply reservation price of milk.

7 The price of concentrated feed is adjusted for the subsidy from the government. 
Because equation (6) is specifying the supply side of the raw milk market, we expect a positive relationship between quantity of supply, $Q_{t}^{p e}$, and the price. The "actual" quantity of supply is unknown when negotiations are conducted at the beginning of each calendar year. So, we have to use the "estimated" total quantity of raw milk production in time $t$, which is unobserved at the time of decision making. To approximate this unobservable variable, following Nerlove and Bessler (2001), we use data on the "observed" supply of raw milk (i.e., supply in previous time periods) and estimate $Q_{t}=b_{1} Q_{t-1}+b_{2} Q_{t-2}+\ldots+b_{p} Q_{t-p}+$ $\mu_{t}+c_{1} \mu_{t-1}+\ldots+c_{q} \mu_{t-q}$ using an autoregressive integrated moving average (ARIMA) process of order $(p, d, q) .^{8}$ Then we replace $\hat{Q}_{t}$ for $Q_{t}^{p e}$ in equation (6).

Dairy processors utilize raw milk as the main input to produce dairy products. The maximum price that processors are willing to offer for the raw milk is the demand reservation price, $P_{t}^{d}$, which depends on the income of processors, the price of substitute inputs, and the quantity of demand at time $t$. Therefore, we specify the demand side of the raw milk market as

$$
P_{t}^{d}=\alpha_{0}+\alpha_{1} W P_{t}+\alpha_{2} D M_{t}+\alpha_{3} Q_{t}^{d e}+u_{t}^{d},
$$

where the unit price of processed milk, $W P_{t}$, represents income from selling dairy products, and $D M_{t}$ and $Q_{t}^{d e}$ denote the price of dry milk as the substitute input and the quantity of demand for raw milk, respectively. An increase in the price of dairy products encourages processors to demand more raw milk for processing and thus offer a higher price for raw milk in the negotiations. Hence, we expect any increase in $W P_{t}$ to positively affect $P_{t}^{d}$. Moreover, when the price of dry milk rises, demand for raw milk and, consequently, $P_{t}^{d}$ would increase. Higher quantity of expected demand, $Q_{t}^{d e}$, will negatively affect $P_{t}^{d}$. Because the negotiations are focused only on the price of raw milk, we assume that there is no excess demand or supply in the market (i.e., $Q_{t}^{d e}=Q_{t}^{p e}$ ). We can use $\hat{Q}_{t}$ to also represent $Q_{t}^{d e}$ when estimating equation (7).

Two econometric issues arise when estimating the bilateral bargaining model specified in the system of equations in equation (5). The first issue is the correlation between dairy price index $\left(W P_{t}\right)$ and the negotiated price of raw milk $\left(P_{t}\right)$. Dairy price index is the weighted average of prices for pasteurized milk, yogurt, and cheese where quantity of demand for each dairy product serves as the respective weight for that product. To address the correlation issue, we use a two-stage estimation method. In the first stage, we regressed $W P_{t}$ on all of the exogenous variables in the system as follows:

$$
W P_{t}=\gamma_{0}+\gamma_{1} Q_{t}+\gamma_{2} D M_{t}+\gamma_{3} F C_{t}+\gamma_{4} L_{t}+\gamma_{5} K_{t}+\varepsilon_{t}
$$

The notation is similar to before except that here $Q_{t}$ is the "observed" quantity of milk that is processed into dairy products, and we equate it to the firms'

8 We select the optimal orders using the Schwarz criterion. 
demand for raw milk. The price of capital input ${ }^{9}$ in the dairy industry is denoted by $K_{t}$. Machinery, buildings, land, vehicles, and durable goods are considered as capital assets.

According to Griliches and Jorgenson (1966), if we assume that there is no direct taxation, then the price of the $j$ th capital service for $i$ th dairy firm in each period satisfies the following relationship:

$$
P_{i j}=q_{i j}\left(r+\delta_{j}-\frac{\dot{q}_{i j}}{q_{i j}}\right) \text { for } j=1,2, \ldots, 5 \text { and } i=1, \ldots, n,
$$

where $q_{i j}$ is the price of the $j$ th investment good for the firm $i, r$ is the rate of return on all capital, $\delta_{j}$ is the rate of replacement of the $j$ th investment good, and $\frac{\dot{q}_{i j}}{q_{i j}}$ is the firm's rate of capital gain on each investment good. Therefore, $\bar{P}_{i}=\frac{\sum_{j=1}^{5} \omega_{i j} P_{i j}}{Q_{i}}$ is the price (or cost) of capital input for firm $i$ to process one unit of milk, $\omega_{i j}$ is the relative share of the capital service $j$ in the value of all capital services for firm $i$, and $Q_{i}$ is the demand for milk by firm $i$. To calculate the capital input price $\left(K_{t}\right)$ for the dairy industry in time $t$, we aggregate the capital price $\left(\bar{P}_{i}\right)$ for all firms in each period using the arithmetic mean. In each period, we use the 5 -year investment deposit rate and linear depreciation rate for $r$ and $\delta_{j}$, respectively. Using all the information, we estimate equation (8) and replace $\widehat{W P}_{t}$ in equation (7) to address the simultaneity problem.

The second problem in estimating the bilateral bargaining model is that both $P_{t}^{s}$ and $P_{t}^{d}$ are latent variables in the system. Dempster, Laird, and Rubin (1977) proposed an iterative algorithm that computes maximum likelihood estimates when the observations are incomplete or there are latent variables in the model. Similar to Dempster, Laird, and Rubin (1977), we use the Monte Carlo expectation maximization (MCEM) algorithm, which has two iterative steps. The first step is called the expectation step (E step), which uses the current estimates of the parameters to create an expected log-likelihood function. Then, the second step, or the maximization step ( $\mathrm{M}$ step), computes parameters that maximize the previously created log-likelihood function. The new estimated maximizing parameters are then used to determine the distribution of the latent variables, and the first step is repeated. The alternation between the $\mathrm{E}$ and $\mathrm{M}$ steps is continued until the sequence of likelihood values converges.

To implement the MCEM algorithm, we follow Wei and Tanner (1990). Let the complete data set be defined by $X_{t}=\left[\begin{array}{ll}P_{t}^{s} & P_{t}^{d} \\ P_{t}\end{array}\right]^{T}$. Then, the log-likelihood

9 To calculate capital input price, we use the results from the annual survey of manufacturing industries in Iran conducted by Statistical Center of Iran since 1972. The survey collects data on all manufacturers with more than 50 employees and a sample of those with 49 employees and less. All variables are measured in nominal terms. 
function with complete information, $l\left(\theta \mid X_{t}\right)$, is

$$
l\left(\theta \mid X_{t}\right)=\log L\left(\theta \mid X_{t}\right)=\sum_{i=1}^{n} \log \left[f_{\theta, t}\left(X_{t}\right)\right]
$$

where $\theta$ is the vector of parameters of interest, and $f_{\theta, t}\left(X_{t}\right)$ is the probability density function (pdf) of the random vector $X_{t}$. In the MCEM algorithm, the E step uses $\theta$ to form $l\left(\theta \mid X_{t}\right)$, and the $M$ step finds the $\theta^{(k)}$ that maximizes $l\left(\theta \mid X_{t}\right)$ where $k$ simply denotes the number of iterations. Thus, at the $(k+1)$ th iteration, the E step computes $Q\left(\theta ; \theta^{(k)}\right)$, where

$$
\mathcal{Q}\left(\theta, \theta^{(k)}\right)=\sum_{t=1}^{n} E_{\theta^{(k)}}\left\{\log \left[f_{\theta}\left(X_{t}\right)\right]\right\}
$$

and

$$
E_{\boldsymbol{\theta}^{(k)}}\left\{\log \left[f_{\boldsymbol{\theta}}\left(X_{t}\right)\right]\right\}=\int_{P_{t}}^{+\infty} \int_{-\infty}^{P_{t}} \log \left[f_{\boldsymbol{\theta}}\left(X_{t}\right)\right] f_{\boldsymbol{\theta}^{(k)}}^{*}\left(p_{t}^{s}, p_{t}^{d}\right) d p_{t}^{s} d p_{t}^{d},
$$

in which $f_{\boldsymbol{\theta}^{(k)}}^{*}\left(p_{t}^{s}, p_{t}^{d}\right)$ denotes the joint pdf of latent variables, which in our case are $P_{t}^{s}$ and $P_{t}^{d}$. The right-hand side in equation (12) is hard to evaluate, leaving the E step untraceable. To resolve the problem, we modify the E step in equation (11) using a Monte Carlo approach as follows:

$$
\mathcal{Q}\left(\boldsymbol{\theta}, \boldsymbol{\theta}^{(k)}\right) \cong \frac{1}{m} \sum_{t=1}^{n} \sum_{i=1}^{m} \log \left[f_{\boldsymbol{\theta}}\left(P_{i, t}^{d}, P_{i, t}^{s}, P_{t}\right)\right] .
$$

The $M$ step then chooses $\theta^{(k+1)}$ to be any value of $\theta \in \Omega$ that maximizes $\mathcal{Q}\left(\theta, \theta^{(k)}\right)$ such that

$$
\theta^{(k+1)}=\arg \max _{\theta} \mathcal{Q}\left(\theta, \theta^{(k)}\right) .
$$

The key point in the MCEM algorithm approach is the pdf of the random vector $X_{t}$, which consists of price variables. Prices are assumed to be normally distributed in economics; however, we assume that negotiated price is bound between reservation prices (i.e., $P_{t}^{s}<P_{t}<P_{t}^{d}$ ) in our bargaining model. Thus, we use a truncated multivariate normal distribution with the density function of

$$
f_{\boldsymbol{\theta}, t}\left(X_{t}\right)=g_{t}(\boldsymbol{\theta})^{-1}(2 \pi)^{\frac{3}{2}}|\boldsymbol{\Sigma}|^{-\frac{1}{2}} \exp \left[-\frac{1}{2}\left(X_{t}-\boldsymbol{\mu}_{t}\right)^{\prime} \boldsymbol{\Sigma}^{-1}\left(X_{t}-\boldsymbol{\mu}_{t}\right)\right],
$$

where

$$
g_{t}(\boldsymbol{\theta})=\int_{-\infty}^{+\infty} \int_{p_{t}^{s}}^{+\infty} \int_{p_{t}^{s}}^{p_{t}^{d}}(2 \pi)^{\frac{3}{2}}|\boldsymbol{\Sigma}|^{-\frac{1}{2}} \exp \left[-\frac{1}{2}\left(X_{t}-\boldsymbol{\mu}_{t}\right)^{\prime} \boldsymbol{\Sigma}^{-1}\left(X_{t}-\boldsymbol{\mu}_{t}\right)\right] d p_{t} d p_{t}^{d} d p_{t}^{s} .
$$


To test whether the estimated parameters are statistically significant, we use the bootstrap method ${ }^{10}$ to calculate the standard error of the parameters $\left(\theta^{*}\right)$ as follows:

$$
\operatorname{SE}(\hat{\theta})=\left[1 / m \sum_{i=1}^{m}\left(\theta_{i}^{*}-\hat{\theta}\right)^{2}\right]^{1 / 2},
$$

where $\hat{\theta}$ is the estimated parameter using the total number of observations. After calculating the standard error of the parameters, we form the $95 \%$ confidence interval as $\bar{\theta} \pm 1.96 * \operatorname{SE}(\hat{\theta})$, in which $\bar{\theta}$ is the mean of bootstrap estimated parameters.

\section{Data}

Time series data for the dairy industry in Iran for the period of 1990-2013 published by the Statistical Center of Iran in statistical yearbooks are used for empirical estimation. Because the quarterly data are not available for some variables, such as milk production, we employ annual data. We estimate the expected quantity of milk, $Q_{t}$, using the annual information on milk production from 1965 to 2013 . Then we include $\hat{Q}_{t}(t=1990-2013)$ in the bargaining model in equation (5).

We use an index price for dairy products as a proxy for the unit price of processed milk, $W P_{t}$. Therefore, $W P_{t}$ is calculated as the weighted average of prices for pasteurized milk, yogurt, and cheese, where the quantity demanded for each dairy product in time $t$ serves as the respective weight for the product.

\section{Empirical Results}

We use the augmented Dickey-Fuller (ADF) approach to test for unit roots in each variable. The results from the ADF test on the residuals show that nonstationary variables in our study are cointegrated, and, except for the quantity of milk production $\left(Q_{t}\right)$, we found all variables to be $I(1)$ - that is, integrated of order one. To estimate expected quantity of milk, $\hat{Q}_{t}$, we employ an autoregressive moving average (ARMA) $(1,4)$. We then use $\hat{Q}_{t}$ in equations $(6)$ and $(7)$.

As explained before, predicted values for the price of dairy products, $\widehat{W P}_{t}$, are used in equation (7). Table 1 presents the results of estimating $W P_{t}$ in equation (8). The estimated coefficients are statistically significant, and the $R^{2}$ (0.89) implies a good fit.

All estimated coefficients have the expected sign. The estimated parameter for $Q_{t}$ shows that as firms process one more million tons of raw milk into dairy products, the price index for dairy products is estimated to increase, on

10 There were 1,800 samples and 23 observations in each sample with replacements. 
Table 1. Estimation of the Price of Dairy Products

\begin{tabular}{llc}
\hline \hline Variables & Coefficient & $t$-Ratio \\
\hline Constant & $-3,889.097^{* * *}$ & -7.607 \\
Quantity of milk processed $\left(Q_{t}\right)$ & $1,307.563^{* * *}$ & 7.878 \\
Dry milk price $\left(D M_{t}\right)$ & $0.077^{* * *}$ & 2.967 \\
Concentrated feed price $\left(F C_{t}\right)$ & $1.951^{* * *}$ & 2.799 \\
Labor price $\left(L_{t}\right)$ & $0.051^{* *}$ & 2.484 \\
Capital input price $\left(K_{t}\right)$ & $1.590^{*}$ & 1.732 \\
$R^{2}=0.89$ & Durbin-Watson statistic $=2.01$ & $F$-statistic $=1,139.452$ \\
\hline \hline
\end{tabular}

Note: Asterisks $\left({ }^{* * *},{ }^{* *},{ }^{*}\right)$ indicate significant at $1 \%, 5 \%$, and $10 \%$, respectively.

Table 2. Diagnostic Test Results for the System of Equations in the Bargaining Mode

\begin{tabular}{lllll}
\hline \hline & Unit Root & Heteroscedasticity & Autocorrelation & Normality \\
\hline$u_{t}^{d}$ & $-5.432(0.001)$ & $0.620(0.612)$ & $1.132(0.350)$ & $1.867(0.393)$ \\
$u_{t}^{s}$ & $-3.964(0.021)$ & $1.53(0.24)$ & $2.01(0.16)$ & $0.28(0.86)$ \\
$u_{t}^{p}$ & $-4.740(0.003)$ & $1.419(0.25)$ & $1.7(0.23)$ & $0.02(0.90)$ \\
\hline \hline
\end{tabular}

Notes: Numbers in parentheses represent $P$ value or marginal significance level against a two-sided alternative. The augmented Dickey-Fuller test is used for testing the null hypothesis of unit root existence. The null hypothesis of homoscedasticity is tested by Breusch-Pagan-Godfrey method. The BreuschGodfrey serial correlation Lagrange multiplier (LM) test and Jaque-Bera statistics are applied for testing autocorrelation and normality, respectively.

average, by 1,307.5 Iranian rials annually, holding all else constant. Because this equation represents the supply of dairy products, the estimated positive relationship between the quantity of supply and the price is as expected. One reason for the increase in $Q$ is consumer support policies by the government that shift demand for dairy products positively. In this case, the excess demand for dairy products raises the dairy prices and therefore encourages the processors to process extra raw milk into dairy products. Similarly, any increase in the price of inputs would positively affect the price index for dairy products.

By replacing $\hat{Q}_{t}$ and $\widehat{W P}_{t}$ into the system of equations in equation (5), we can estimate the bargaining model. First, we test for the misspecification (i.e., unit root, heteroscedasticity, autocorrelation, and normality [based on generalized residuals]) and report the results in Table 2. Statistics show that the residuals are stationary, homoscedastic, not serially correlated, and normal. Therefore, it is concluded that the model is not misspecified and the variables are cointegrated.

Table 3 shows the result of estimating the bargaining model. All estimated parameters are statistically significant at the $5 \%$ level and have the expected sign. The first panel in Table 3 shows that $P_{t}^{d}$, the processors' demand reservation price, is positively related to the price of dairy products and dry milk, but negatively related to the quantity of milk processed. Higher prices for dairy products mean higher average revenues for the processors. Dry milk powder 
Table 3. Estimation of the Bargaining Model

\begin{tabular}{lll}
\hline \hline Variable & Parameter & Estimation \\
\hline Supply reservation $\left(P_{t}^{s}\right)$ & & \\
$\quad$ Constant & $\alpha_{0}$ & $-100.01(30.8)$ \\
Feed concentrate price $\left(F C_{t}\right)$ & $\alpha_{1}$ & $0.73(0.23)$ \\
Labor price $\left(L_{t}\right)$ & $\alpha_{2}$ & $0.017(0.008)$ \\
Raw milk supply $\left(\hat{Q}_{t}\right)$ & $\alpha_{3}$ & $50.32(15.8)$ \\
Demand reservation $\left(P_{t}^{d}\right)$ & & \\
Constant & $\beta_{0}$ & $300.5(60.2)$ \\
Dairy price $\left(\widehat{W P}_{t}\right)$ & $\beta_{1}$ & $0.28(0.05)$ \\
Dry milk price $\left(D M_{t}\right)$ & $\beta_{2}$ & $0.008(0.004)$ \\
Raw milk demand $\left(\hat{Q}_{t}\right)$ & $\beta_{3}$ & $-100.2(40.5)$ \\
Negotiated price $\left(P_{t}\right)$ & $(\tau)$ & $0.31(0.05)$ \\
$\quad$ Demand reservation price $\left(P_{t}^{d}\right)$ & $(1-\tau)$ & $0.69(0.05)$ \\
Supply reservation price $\left(P_{t}^{s}\right)$ & & \\
\hline \hline
\end{tabular}

Note: Asymptotic standard errors in parentheses.

can be substituted for raw milk in making dairy products, and therefore, any increase in its price affects the demand for raw milk positively. In both cases, processors are encouraged to bid higher for raw milk. The expected negative sign for the estimated parameter of variable $\hat{Q}_{t}$ implies that as the demand for raw milk increases, processors reduce their bid for raw milk to decrease processing cost.

The second panel of the table reports the estimated parameters for the farmers' supply reservation price equation. According to the results, prices of concentrated feed and labor have significant positive effects on $P_{t}^{s}$, which is intuitive and implies that when the prices of inputs rise, farmers demand higher prices at the negotiation table. There is also a positive relationship between the quantity of raw milk supplied and the supply reservation price.

The total gain from the bargaining process increases when both parties agree on a negotiated price, which is achievable if $P_{t}^{s}$ decreases or $P_{t}^{d}$ increases. The share of each party from the total payoffs depends on their respective bargaining power. The last panel of Table 3 shows the estimation results for the negotiated price equation. The bargaining power for farmers is denoted by $\tau$ and that of processors by $1-\tau$, which are estimated at 0.31 and 0.69 , respectively. It is clear that the farmers and the processors have unequal bargaining power so that the processors gain more benefits from the negotiations.

There are some reasons why the processors have higher bargaining power. First is that milk is perishable, and it is almost impossible for farmers to store it. Second is the lack of active marketing cooperatives to represent numerous small farmers, while a few large processors produce the main share of dairy products in the market. Hence, processors are stronger and more effective in milk price formation negotiation than farmers. 
Table 4. Elasticity of Negotiated Milk Price with Respect to Determinants of the $P_{t}^{s}$ and $P_{t}^{d}$

\begin{tabular}{lll}
\hline \hline Factors & $\begin{array}{l}\text { Elasticity of } P_{t} \\
\text { When Reservation } \\
\text { Prices Increase }\end{array}$ & $\begin{array}{l}\text { Elasticity of } P_{t} \\
\text { When Reservation } \\
\text { Prices Decrease }\end{array}$ \\
\hline Dairy price $\left(W P_{t}\right)$ & 0.34 & 0.6 \\
Dry milk price $\left(D M_{t}\right)$ & 0.02 & 0.03 \\
Feed concentrate price $\left(F C_{t}\right)$ & 0.15 & 0.27 \\
Labor price $\left(L_{t}\right)$ & 0.06 & 0.1 \\
\hline \hline
\end{tabular}

Further evaluation of the elasticities for $P_{t}^{s}$ and $P_{t}^{d}$ show that a $1 \%$ increase in the prices of concentrated feed and labor leads to an increase in $P_{t}^{s}$ by $0.42 \%$ and $0.16 \%$, respectively. This means that feed prices have a larger impact on farmers' supply reservation price. Thus, policy makers who are concerned about the price of dairy products (to support consumers) should be alerted by the increase in feed prices rather than farm labor wages. Similarly, a $1 \%$ increase in the price of dairy products and dry milk would increase $P_{t}^{d}$ by $0.95 \%$ and $0.05 \%$, respectively. Therefore, contrary to the concerns of dairy farmers, dry milk prices have minimal impact on the processors' demand reservation price.

When $P_{t}^{d}$ and $P_{t}^{s}$ increase, we expect the negotiated price of raw milk to change depending on the bargaining power of the players. Because the bargaining power is asymmetric in this market (i.e., $\hat{\tau} \neq 0.5$ ), the price elasticity of raw milk when factors have a positive effect on reservation prices (i.e., a change in $F C_{t}$ and $L_{t}$ that raises $P_{t}^{s}$ or a change in $W P_{t}$ and $D M_{t}$ that increases $P_{t}^{d}$ ) is different from when they have a negative effect. For instance, the processors' share is $69 \%$ when the total gain from trade in raw milk is increasing, and only $31 \%$ when it is decreasing. The bargaining gain for farmers is vice versa. We calculate the share of each party from the total gain using the estimated bargaining power parameter $\tau$ and the factor elasticities reported in Table 4.

Table 4 shows the elasticity of negotiated price when $P_{t}^{s}$ and $P_{t}^{d}$ increase or decrease because of the change in each factor. The logic of using these elasticities is that the percentage change in reservation prices is not equivalent to the percentage change in the negotiated price when the bargaining power is asymmetric. To elaborate, consider the price of dairy products as a changing factor for the demand reservation price. Using the estimations in Table 3, we expect that each $10 \%$ increase in the price of dairy products results in a $9.5 \%$ increase in $P_{t}^{d}$. However, the first column in Table 4 shows the elasticity of negotiated price when reservation prices increase. In this scenario, the negotiated price of milk will only increase by $3.4 \%$ in response to a $10 \%$ increase in the price of dairy products. If the bargaining power was 0.5 , then the price of milk would increase by $4.75 \%$. Similarly, when the price of feed increases by $10 \%$, the supply reservation price increases by $4.2 \%$, thereby causing an increase of $1.5 \%$ in the 
price of milk, whereas in case of symmetric bargaining power, the price of milk would increase by $2.1 \%$. The elasticities of dry milk and labor $\left(D M_{t}\right.$ and $\left.L_{t}\right)$ can be evaluated similarly.

The elasticity of the negotiated price of milk with respect to the factors when $P_{t}^{s}$ and $P_{t}^{d}$ are decreasing is presented in the last column of Table 4. For instance, a $10 \%$ decrease in the price of dairy products implies a $6 \%$ decline in the price of raw milk. We can use the elasticities to describe the effect of changes in $D M_{t}$, $L_{t}$, and $F C_{t}$ on the negotiated price of raw milk.

\section{Conclusion}

This article investigates the negotiation process in which the price of raw milk is formed in Iran and estimates the effects of reservation supply and demand in the bilateral bargaining model. We apply the MCEM algorithm to estimate the generalized Nash bargaining model. This method properly estimates the parameters of our model, including the two latent variables-namely, reservation price for processors $\left(P_{t}^{d}\right)$ and for farmers $\left(P_{t}^{s}\right)$. The reservation prices are determined by the cost and revenue factors. Including the reservation price equations in the model to determine the negotiated price enables us to measure the average bargaining power for dairy farmers and processors in the period of the study and to identify the factors that underpin the bargaining power of each party.

The results from this study show that processors' representatives were more successful in bargaining with the farmers' representatives. The average bargaining power for the processors is 0.69 , whereas it is 0.31 for farmers. This asymmetry of bargaining power causes unbalanced distribution of gains in the milk market showing that the MIMT has failed to meet its objective of creating a fair bargaining environment. ${ }^{11}$ One possible reason that the processors have greater bargaining power is that dairy farmers are represented by government officials from the Department of Agriculture for most of the studied years. From the government's perspective, lower milk prices are favored. A major policy goal of the government is to encourage dairy consumption. To realize this goal, they attempt to keep dairy prices at an affordable level for consumers. Therefore, government officials are not motivated to negotiate the highest possible price for raw milk in the bargaining process.

It is also important to note that the supply quantity is not discussed in the negotiations. The government always encourages higher productivity to reach self-sustaining production levels, and therefore, quantity control is not regarded as an issue. On the other hand, either the farmers are not members of a marketing cooperative or their cooperative is not successful in controlling the production

11 This would be met if the bargaining power estimation were 0.5 for each party. Thanks to the anonymous reviewer for reminding us of this point. 
level. Most cooperatives limit their activities to providing affordable inputs to farmers; supply control is not a goal. To increase farmers' benefits in the raw milk market, we suggest the development of marketing cooperatives to better organize and effectively represent farmers in the bargaining process.

Dairy farmers are often concerned about the adverse effect of lower prices on their income and excessive importation of dry milk as the substitute for raw milk in the dairy processing industry. However, the elasticity analysis shows that the percentage change in the negotiated price of raw milk with respect to change in the price of dry milk is far less than the impact of change in the price of feed concentrate. So, the impact of higher feed prices should be of more concern to farmers than the importation of dry milk. The government supports dairy farmers by distributing subsidized concentrated feed to reduce their production costs. Production support policies have been effective to some extent, but whether they have improved farmers' bargaining power during past decades is beyond the scope of this study. Further research is needed to analyze the dynamics of bargaining power in the dairy market in Iran.

\section{References}

Ahmadi Shadmehri, M.T., and M. Ahmadi. "Vertical Asymmetric Price Transmission on the Iran's Milk Market.” [In Farsi.] Quarterly Journal of Quantitative Economics 7(Fall 2010):133-56.

Binmore, K., A. Rubinstein, and A. Wolinsky. "The Nash Bargaining Solution in Economic Modelling.” RAND Journal of Economics 17(July 1986):176-88.

Bonnet, C., and Z. Bouamra-Mechemache. "Organic Label, Bargaining Power, and ProfitSharing in the French Raw Milk Market.” American Journal of Agricultural Economics 98(August 2015):113-33.

Chizari, A.H., Z. Shokoohi, and H. Salami. "Estimating Market Power in Iranian Dairy Processing Industry with Dynamic Imperfect Competition Model.” Journal of Agricultural Science and Technology 20(January 2018):1-12.

Chizari, A.H., Z. Shokoohi, H. Salami, and S.S. Hosseini. "Existence of Habits and Empirical Demand Analysis: A Case Study for Urban Households' Dairy Products Demand in Iran.” [In Farsi.] Journal of Agricultural Economics 9(2015):19-35.

Dempster, A.P., N.M. Laird, and D.B. Rubin. "Maximum Likelihood from Incomplete Data via the EM Algorithm." Journal of the Royal Statistical Society: Series B (Methodological) 39(January 1977):1-38.

Folwell, R.J., R.C. Mittelhammer, and Q. Wang. "An Empirical Bargaining Model of Price Discovery: An Application to the Washington/Oregon Asparagus Industry.” International Food and Agribusiness Management Review 1(January 1998):525-37.

Griliches, Z., and D.W. Jorgenson. "Sources of Measured Productivity Change: Capital Input.” American Economic Review 56(March 1966):50-61.

Iran Ministry of Industry, Mine, and Trade (MIMT). Internet site: http://en.mimt.gov.ir/ (Accessed 2013).

Iran Ministry of Industry, Mine, and Trade, Consumers and Producers Protection Organization (CPPO). Internet site: http://cppo.mimt.gov.ir (Accessed 2016). 
Moghaddasi, R., and R. Rahimi. “A Study on Price Transmission in Milk Market.” [In Farsi.] Economics Journal 7(June 2013):9-26. (in Farsi)

Muthoo, A. Bargaining Theory with Applications. New York: Cambridge University Press, 1999.

Napel, S. Bilateral Bargaining: Theory and Applications. Berlin: Springer-Verlag, 2002.

Nash, J.F. Jr. “The Bargaining Problem.” Econometrica 18(April 1950):155-62.

Nerlove, M., and D. Bessler. "Expectations, Information and Dynamics." Handbook of Agricultural Economics. Vol. 1, Part A. B.L. Gardner and G.C. Rausser, eds. Amsterdam: Elsevier Science, 2001, pp. 155-206.

Noton, C., and A. Elberg. "Revealing Bargaining Power through Actual Wholesale Prices." Working Papers 51, Santiago, Chile: Facultad de Economía y Empresa, Universidad Diego Portales, 2014.

Oczkowski, E. “The Econometrics of Markets with Quantity Controls.” Applied Economics 23(March 1991):497-504.

Pishbahar, E., and M. Kheiri Nataj-Firozjah. "Evaluation the Dairy Demand of Iran Using Almost Ideal Demand System (AIDS)." [In Farsi.] Iranian Journal of Agricultural Economics and Development Research 45(2015) 693-701.

Prasertsri, P., and R.L. Kilmer. "The Bargaining Strength of a Milk Marketing Cooperative.” Agricultural and Resource Economics Review 37(October 2008):204-10.

Roth, A.E. Axiomatic Models of Bargaining. Berlin: Springer-Verlag, 1979.

- "A Note on Risk Aversion in a Perfect Equilibrium Model of Bargaining." Econometrica 53(January 1985):207-12.

Rubinstein, A. "Perfect Equilibrium in a Bargaining Model." Econometrica 50(January 1982):97-109.

Statistical Center of Iran. Iran Statistical Yearbook. Tehran, Iran: Statistical Center of Iran, 1990-2013.

Suh, S.C., and Q. Wen. "Multi-agent Bilateral Bargaining and the Nash Bargaining Solution." Journal of Mathematical Economics 42(February 2006):61-73.

Wei, G.C., and M. Tanner. "A Monte Carlo Implementation of the EM Algorithm and the Poor Man's Data Augmentation Algorithms." Journal of the American Statistical Association 85(September 1990):699-704. 